\title{
Quatre poètes dans l'Europe monde. Yves Bonnefoy, Michel Deguy, Márton Kalász, Wulf Kirsten, sous la direction de Stéphane Michaud
}

\section{Fabio Scotto}

\section{(2) OpenEdition}

\section{Journals}

Edizione digitale

URL: http://journals.openedition.org/studifrancesi/7035

DOI: $10.4000 /$ studifrancesi.7035

ISSN: 2421-5856

\section{Editore}

Rosenberg \& Sellier

\section{Edizione cartacea}

Data di pubblicazione: 1 septembre 2010

Paginazione: 408

ISSN: 0039-2944

\section{Notizia bibliografica digitale}

Fabio Scotto, «Quatre poètes dans I'Europe monde. Yves Bonnefoy, Michel Deguy, Márton Kalász, Wulf Kirsten, sous la direction de Stéphane Michaud», Studi Francesi [Online], 161 (LIV | II) | 2010, online dal 30 novembre 2015, consultato il 07 janvier 2021. URL: http://journals.openedition.org/studifrancesi/ 7035 ; DOI: https://doi.org/ERREUR PDO dans /localdata/www-bin/Core/Core/Db/Db.class.php L.34 SQLSTATE[HYO00] [2006] MySQL server has gone away

Questo documento è stato generato automaticamente il 7 janvier 2021.

\section{(†)

Studi Francesi è distribuita con Licenza Creative Commons Attribuzione - Non commerciale - Non opere derivate 4.0 Internazionale. 


\title{
Quatre poètes dans l'Europe monde. Yves Bonnefoy, Michel Deguy, Márton Kalász, Wulf Kirsten, sous la direction de Stéphane Michaud
}

\author{
Fabio Scotto
}

\section{NOTIZIA}

Quatre poètes dans l'Europe monde. Yves Bonnefoy, Michel Deguy, Márton Kalász, Wulf Kirsten, sous la direction de Stéphane MICHAUD, Paris, Klincksieck, 2009 («Circare», 4), pp. 234.

1 Sono qui raccolti gli Atti di un Convegno che ha avuto luogo a Parigi «à l'automne 2007» (p. 8), Atti, scrive il Curatore, «retravaillés pour l'édition, [...] présentés au cours d'un colloque qui s'est tenu à la Bibliothèque nationale de France et à la Sorbonne» (p. 14). Dal volume relativo al Convegno svoltosi in presenza dei quattro poeti oggetto di studio espungiamo, data la sua impostazione comparatistica, quanto riguarda direttamente la poesia francese.

2 Stéphane MICHAUD nell'Introduction (pp. 7-14) presenta i poeti invitati mostrandone il comune interesse per la traduzione come momento creativo e riflessivo, idea poi ripresa nella sua comunicazione Poésie européenne, poésie mondiale: la traduction généralisée (pp. 147-163), in cui individua nella «traduction comme constitutive, constructrice d'Europe» (p. 149) la questione fondamentale che il convegno si è posto, nella duplice articolazione di ricerca di modalità espressive atte a tradurre l'artista in un linguaggio e di fondazione di una comunità tramite l'atto poetico.

Martin RUEFF (Michel Deguy: le poème de la fidélité, pp. 17-44), muovendo da Baudelaire (Le Balcon) e Du Bellay, individua nella fedeltà un «opérateur de connexion» e il luogo costitutivo della definizione del soggetto e della sua memoria, poi studiando in Deguy la 
«poétique de l'attachement» nella sua accezione lirica che avvince poesia e traduzione come «anamnèse amnésique» e «ana-kata-chronisme».

4 Jan Volker RÖHNERT (Kirsten et Deguy, deux poètes en leur paysage, pp. 107-115) individua nella lezione cendrarsiana e nicciana la matrice della «danse du paysage» di Deguy, che tende a far coincidere lo spazio con il luogo della realtà del linguaggio.

Philippe DAROS («Il reste à faire le négatif», pp. 127-145) prende spunto da un commento del 1988 di Yves Bonnefoy all'assunto di Kafka «Il reste à faire le négatif, le positif nous est déjà donné» per mostrare, da una prospettiva estetico-filosofica, la valenza di taluni concetti-chiave della poetica di Bonnefoy, dal «monde-image» alla «présence», attraverso un confronto con la «non-présence» di Blanchot e l'«imprésenté» di LacoueLabarthe.

6 Nella sezione dedicata ai testi dei quattro poeti invitati, Yves BONNEFoY (L'Europe et la poésie: la tâche du traducteur, pp. 195-203), attraverso una denuncia dell'insufficiente capacità unificatrice delle lingue europee, individua nella catastrofe di Babele il momento di nascita dell'esigenza di tradurre. Rammentando le resistenze dell'amico P. Celan a farsi tradurre in francese e confutando Benjamin egli giunge a definire la sua idea di traduzione come atto poetico di chi avverta «la pleine immédiateté dans les choses et les êtres» al di là di ogni fedeltà alla sintassi o alla specularità letteralistica, ma in una fedeltà alla musica dell'originale però da ricrearsi su un nuovo terreno affine, ma dissimile. Preoccupazione analoga a quella cui alludono le Proses (pp. 205-212) di Michel DEGUY, che articolano mentalmente il rapporto fra poesia e musica in una disseminazione fortemente intertestualizzata che fa della «privation» una negatività potenzialmente feconda di istanze generative. In appendice un Index des noms de lieux (pp. 225-226) e un Index des noms (pp. 227-232). 